\title{
Article \\ The Mechanical Resistance of Asphalt Mixture with Steel Slag to Deformation and Skid Degradation Based on Laboratory Accelerated Heavy Loading Test
}

\author{
Jiasheng Li, Jianying Yu, Shaopeng Wu * and Jun Xie
}

check for

updates

Citation: Li, J.; Yu, J.; Wu, S.; Xie, J.

The Mechanical Resistance of Asphalt Mixture with Steel Slag to Deformation and Skid Degradation Based on Laboratory Accelerated

Heavy Loading Test. Materials 2022, 15, 911. https://doi.org/10.3390/ ma15030911

Academic Editor: Miguel Ángel Sanjuán

Received: 15 December 2021

Accepted: 20 January 2022

Published: 25 January 2022

Publisher's Note: MDPI stays neutral with regard to jurisdictional claims in published maps and institutional affiliations.

Copyright: (C) 2022 by the authors. Licensee MDPI, Basel, Switzerland. This article is an open access article distributed under the terms and conditions of the Creative Commons Attribution (CC BY) license (https:// creativecommons.org/licenses/by/ $4.0 /)$.
State Key Laboratory of Silicate Materials of Architectures, Wuhan University of Technology, Wuhan 430070, China; lijiasheng@whut.edu.cn (J.L.); jyyu@whut.edu.cn (J.Y.); xiejun3970@whut.edu.cn (J.X.) * Correspondence: wusp@whut.edu.cn

\begin{abstract}
Steel slag is a main form of solid waste. Using this component to replace part of the aggregate in an asphalt mixture is an effectively way of treating solid waste. To study the performance degradation of asphalt mixture with various content of steel slag under heavy loading, some largesized basalt hot mixed asphalt mixture (BHMA) and steel slag hot mixed asphalt mixture (SHMA) in a form of specimens were prepared and a heavy loading wheel tracking test was conducted. The aggregate characteristics of basalt and steel slag were measured. The deformation and skid resistance of the asphalt mixture with different content of steel slag was tested and analyzed. Due to the particle characteristics of steel slag aggregate, it was found that a low content of steel slag can effectively improve the resistance to deformation and skid resistance of the asphalt mixture under heavy loading. The response of SHMA can still meet the pavement technical requirement after long-term heavy loading service. The main change in the mixture under heavy loading is the crushing of the 9.5-16 mm aggregate, and the content of this part also significantly affects the deformation. This study explains the mechanism of degradation of SHMA under heavy loading: the large aggregate is crushed and forms a new aggregate skeleton structure.
\end{abstract}

Keywords: asphalt mixture; steel slag; heavy loading; aggregate analysis; permanent deformation; skid resistance; aggregate sieving

\section{Introduction}

In recent years, the ever-developing transportation and construction industry has required a massive quantity of aggregates. However, the limited quantity of natural aggregate resources has made it increasingly difficult to meet the demand. Therefore, it is an effective method to substitute natural aggregates with recycled aggregates and other resources [1-4].

As an industrial by-product generated from steel tailing waste, with the development of steel manufacture, an overabundant amount of steel slag has become a threat to the environment in recent years. One solution to this problem is recycling and utilization of steel slag in road construction. Generally, steel slag is composed of $\mathrm{SiO}_{2}, \mathrm{CaO}, \mathrm{MgO}, \mathrm{FeO}_{\mathrm{n}}$ and others $\left(\mathrm{Al}_{2} \mathrm{O}_{3}, \mathrm{MnO}, \mathrm{P}_{2} \mathrm{O}_{5}, \mathrm{f}-\mathrm{CaO}, \mathrm{f}-\mathrm{MgO}\right.$, etc.). Because of the free $\mathrm{CaO}$ (f-CaO), steel slag aggregate may expand during its service life and result in a performance decline on pavement, such as permanent deformation, cracking and flushing [5].

However, it was found that once the expansion is resolved by sufficient aging, steel slag can improve the performance characteristics of asphalt mixture, such as a higher dynamic modulus and tensile strength, decreased deformation and improved rutting and cracking resistance [6-9]. Research shows that aging in air for a certain time can reduce the content of $\mathrm{f}-\mathrm{CaO}$ in steel slag and eliminate the effect of expansion [10]. Wu studied the utilization of steel slag aggregate in SMA mixtures and found that steel slag in SMA mixtures both enhanced the ability of resisting permanent deformation at high temperature 
and the resistance to low temperature cracking, compared with basalt [11]. Xie researched the recycling of basic oxygen furnace (BOF) slag in asphalt mixtures. They found that the addition of BOF could significantly improve the mechanical strength and moisture damage resistance [12-14]. Furthermore, SHMA shows a better skid resistance because of its high strength and irregular shape $[15,16]$.

With the rapid development of the transportation industry, the traffic pressure on highways is climbing year by year. Driven by economic interests, overloaded trucks are appearing frequently on highways. At present, the average axle load of heavy vehicles is about 12-18 $\mathrm{t}$, and the tire pressure is about $0.8-1.1 \mathrm{MPa}$ [17]. When overloaded, the actual axle load of trucks could be up to $24 \mathrm{t}$ and the pressure could take $100 \%$ more than its allowance, which has brought a serious burden on the pavement [18]. With the compacting, wearing and polishing of overloaded vehicle, the strength and skid resistance of pavements will decrease quickly, and it will greatly reduce their service life [19].

At present, most of the research on SHMA focuses on the performance change under a standard load, which is $0.7 \mathrm{MPa}$, while the studies on the performance degradation under heavy loading are relatively few [20-23]. It has been proven that the addition of steel slag could increase the mechanical strength of asphalt mixtures under a standard load. Therefore, it is meaningful to research whether steel slag can improve the performance of asphalt mixture under heavy loading. In this study, aggregate characteristics of basalt and steel slags are quantized and measured. The performance degradation of various SHMA under heavy loading is compared and evaluated. The rutting performance, skid resistance and aggregate grading variation are analyzed to reveal the influence of heavy loading on the performance of SHMA. The performance of BHMA under heavy loading is studied for contrast. This study proposes an explanation for the mechanism of performance degradation of SHMA under heavy loading. Those analysis results will provide significant information for decision-makers to increase available aggregates and the utilization of industrial by-products.

\section{Materials and Experimental Program}

\subsection{Materials}

The coarse aggregate in SHMA was hot-splashing steel slag produced by Sheng Xiang New Eco-friendly Materials Co. Ltd., Guangxi, China. The natural basalt aggregate was mined from Inner Mongolia, China. The chemical composition of the steel slag aggregate is listed in Table 1.

Table 1. Main chemical composition of the steel slag aggregate.

\begin{tabular}{cccccccc}
\hline Chemical Composition & $\mathrm{SiO}_{\mathbf{2}}$ & $\mathbf{C a O}$ & $\mathbf{M g O}$ & $\mathbf{F e O}_{\mathbf{n}}$ & $\mathbf{A l}_{\mathbf{2}} \mathbf{O}_{\mathbf{3}}$ & $\mathbf{M n O}$ & $\mathbf{P}_{\mathbf{2}} \mathbf{O}_{\mathbf{5}}$ \\
\hline Steel slag & 19.40 & 41.60 & 5.36 & 22.40 & 3.12 & 1.57 & 1.29 \\
\hline
\end{tabular}

The basic properties of steel slag coarse aggregate and natural basalt coarse aggregate were tested according to GB/T 24765-2009 [24] and JTG E42-2005 [25] and shown in Tables 2 and 3 .

Table 2. Basic properties of steel slag coarse aggregate.

\begin{tabular}{|c|c|c|c|c|c|}
\hline \multicolumn{2}{|c|}{ Test Items } & \multirow[t]{2}{*}{ Units } & \multirow{2}{*}{$\begin{array}{c}\text { Results } \\
3.386\end{array}$} & \multirow[t]{2}{*}{ Requirements } & \multirow[t]{2}{*}{ Specification } \\
\hline & $9.5-16 \mathrm{~mm}$ & & & & \\
\hline Apparent & $4.75-9.5 \mathrm{~mm}$ & & 3.426 & $\geq 2.9$ & \\
\hline specific gravity & $2.36-4.75 \mathrm{~mm}$ & & 3.465 & & \\
\hline & $9.5-16 \mathrm{~mm}$ & & 1.7 & & $10304-2005$ \\
\hline Water absorption & $4.75-9.5 \mathrm{~mm}$ & $\%$ & 2.4 & $\leq 3.0$ & \\
\hline & $2.36-4.75 \mathrm{~mm}$ & & 2.9 & & \\
\hline \multicolumn{2}{|c|}{ Crushed stone value } & $\%$ & 18.9 & $\leq 22$ & T0316-2005 \\
\hline \multirow{2}{*}{\multicolumn{2}{|c|}{ Los Angeles abrasion }} & $\%$ & 20.4 & $\leq 22$ & T0317-2005 \\
\hline & & & 5 & $\geq 4$ & T0616-2000 \\
\hline \multicolumn{2}{|c|}{ Polished stone value } & PSV & 61.5 & $\geq 45$ & T0312-2005 \\
\hline
\end{tabular}


Table 3. Basic properties of basalt coarse aggregate.

\begin{tabular}{|c|c|c|c|c|c|}
\hline \multicolumn{2}{|c|}{ Test Items } & \multirow[t]{2}{*}{ Units } & \multirow{2}{*}{$\begin{array}{c}\text { Results } \\
2.974\end{array}$} & \multirow[t]{2}{*}{ Requirements } & \multirow[t]{2}{*}{ Specification } \\
\hline \multirow{4}{*}{$\begin{array}{c}\text { Apparent } \\
\text { specific gravity }\end{array}$} & $9.5-16 \mathrm{~mm}$ & & & & \\
\hline & $4.75-9.5 \mathrm{~mm}$ & & 2.995 & $\geq 2.6$ & \multirow{5}{*}{ T0304-2005 } \\
\hline & $2.36-4.75 \mathrm{~mm}$ & & 2.908 & & \\
\hline & $9.5-16 \mathrm{~mm}$ & & 0.4 & & \\
\hline \multirow[t]{2}{*}{ Water absorption } & $4.75-9.5 \mathrm{~mm}$ & $\%$ & 0.7 & $\leq 2.0$ & \\
\hline & $2.36-4.75 \mathrm{~mm}$ & & 0.7 & & \\
\hline \multicolumn{2}{|c|}{ Crushed stone value } & $\%$ & 19.2 & $\leq 22$ & T0316-2005 \\
\hline \multirow{2}{*}{\multicolumn{2}{|c|}{$\begin{array}{l}\text { Los Angeles abrasion } \\
\text { Adhesion level }\end{array}$}} & $\%$ & 22.7 & $\leq 22$ & T0317-2005 \\
\hline & & & 4 & $\geq 4$ & T0616-2000 \\
\hline \multicolumn{2}{|c|}{ Polished stone value } & PSV & 55.2 & $\geq 42$ & T0312-2005 \\
\hline
\end{tabular}

Due to the high number of voids in steel slag fine aggregate, the asphalt content in the mixtures would significantly increase, resulting in increasing costs and a waste of resources [7]. Therefore, the basalt fine aggregate was selected for both SHMA and BHMA.

Styrene-butadiene-styrene block copolymer (SBS) asphalt was selected as binder in asphalt pavement mixtures due to its high skid resistance, high rutting resistance and temperature stability. The basic properties of SBS asphalt are illustrated in Table 4 according to the JTG E20-2011 [26] standards.

Table 4. Basic properties of SBS asphalt binder.

\begin{tabular}{|c|c|c|c|c|}
\hline \multicolumn{2}{|c|}{ Test Items } & Results & Requirements & Specification \\
\hline \multicolumn{2}{|c|}{ Penetration $25^{\circ} \mathrm{C}, 100 \mathrm{~g}, 5 \mathrm{~s}(0.1 \mathrm{~mm})$} & 76.2 & $60 \sim 80$ & T0604-2011 \\
\hline \multicolumn{2}{|c|}{ Softening point $\left({ }^{\circ} \mathrm{C}\right)$} & 63.6 & $\geq 60$ & T0606-2011 \\
\hline \multicolumn{2}{|c|}{ Ductility $5 \mathrm{~cm} / \mathrm{min}, 5^{\circ} \mathrm{C}(\mathrm{cm})$} & 51.2 & $\geq 30$ & T0605-2011 \\
\hline \multicolumn{2}{|c|}{ Density $15^{\circ} \mathrm{C}\left(\mathrm{g} / \mathrm{cm}^{3}\right)$} & 1.031 & 1 & T0625-2011 \\
\hline \multicolumn{2}{|c|}{ Solubility (TCE) (\%) } & 99.8 & $\geq 99$ & T0607-2011 \\
\hline \multirow{3}{*}{ Aging $163^{\circ} \mathrm{C}, 5 \mathrm{~h}$} & Mass change $(\%)$ & 0.4 & \pm 1.0 & T0610-2011 \\
\hline & $\begin{array}{c}\text { Penetration ratio } \\
25^{\circ} \mathrm{C}(\%)\end{array}$ & 83.3 & $\geq 60$ & T0604-2011 \\
\hline & $\begin{array}{c}\text { Residual } \\
\text { ductility } 5{ }^{\circ} \mathrm{C} \\
(\mathrm{cm})\end{array}$ & 32.3 & $\geq 20$ & T0605-2011F \\
\hline
\end{tabular}

The asphalt mixture was prepared according to JTG E20-2011 [26]. The AC-13 product was applied on the upper pavement. The grading curve of BHMA is shown in Figure 1. The AC- 13 BHMA gradings were $28 \% 10-16 \mathrm{~mm}$ basalt, $28 \% 5-10 \mathrm{~mm}, 14 \% 3-5 \mathrm{~mm}$, $26 \% 0-3 \mathrm{~mm}$, and $4 \%$ basalt powder filler. In order to ensure the consistency of grading, the basalt in BHMA was replaced by equal volume steel slag according to its density. The AC13 SHMA grading reached the following values: $29 \% 9.5-16 \mathrm{~mm}$ basalt, $28 \% 4.75-9.5 \mathrm{~mm}$, $15 \%$ 2.36-4.75 mm, $24 \% 0-2.36 \mathrm{~mm}$, and $4 \%$ basalt powder filler.

\subsection{Specimen Preparation}

According to the content of steel slag aggregate, specimens were divided into five types-SM (steel slag mixture)-0, SM-25, SM-50, SM-75 and SM-100. SM-25 meant it contained $25 \%$ steel slag aggregate and $75 \%$ basalt aggregate. Therefore, SM- 0 was pure BHMA and SM-100 was pure SHMA.

Large-sized specimens were adopted in this study to reduce the influence caused by specimen boundary $[27,28]$. The large-sized asphalt mixture specimens had a length of $1000 \mathrm{~mm}$, width of $500 \mathrm{~mm}$ and height of $40 \mathrm{~mm}$. Aggregate and SBS asphalt were preheated up to $165^{\circ} \mathrm{C}$ and compacted by a steel roller. The asphalt content was equal to $4.4 \%$. The final percentage of SM-0 components were $4.4 \%$ SBS bitumen, $26.8 \% 9.5-16 \mathrm{~mm}$ basalt, $26.8 \% 4.75-9.5 \mathrm{~mm}, 13.4 \% 2.36-4.75 \mathrm{~mm}, 24.8 \% 0-2.36 \mathrm{~mm}$ and $3.8 \%$ basalt powder filler. The composition of the other specimens can be calculated from the content and 
density of steel slag. The finished specimens were left at room temperature for $24 \mathrm{~h}$ to reach a stable structure and conditioned in a testing environment for at least $6 \mathrm{~h}$ before the test.

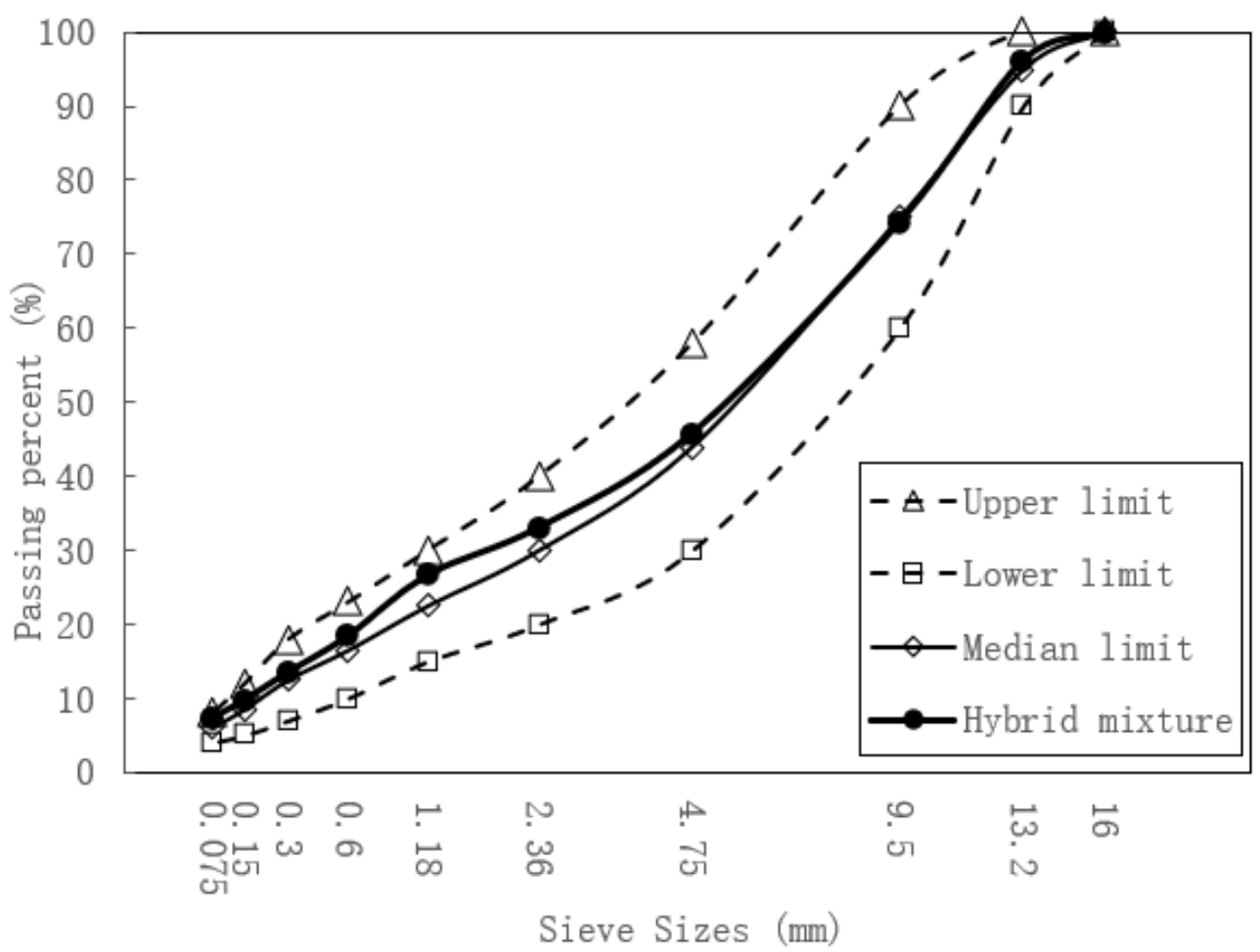

Figure 1. AC-13 grading curve of BHMA.

\subsection{Accelerated Testing Plan}

The tests were conducted in a multifunctional pavement material tester (MPT) developed by Wuhan University of Technology (Figure 2). Its functional part was a rubber wheel with a width of $40 \mathrm{~mm}$ that moved on two steel rails. The contact area was represented by an area of $1200 \mathrm{~mm}^{2}$. The loading cylinder applied a dynamic equilibrium pressure to the specimens, ranging from 0 to $30 \mathrm{MPa}$. The testing condition, such as temperature, UV, oxygen concentration, humidity, etc., were separately controlled by different modules. In this study, the testing conditions were set to a temperature of $60^{\circ} \mathrm{C}$, a humidity of $40 \%$ and a speed of 12 cycles/min according to relevant studies [28]. Displacement sensors recorded the real-time deformation of the specimens.

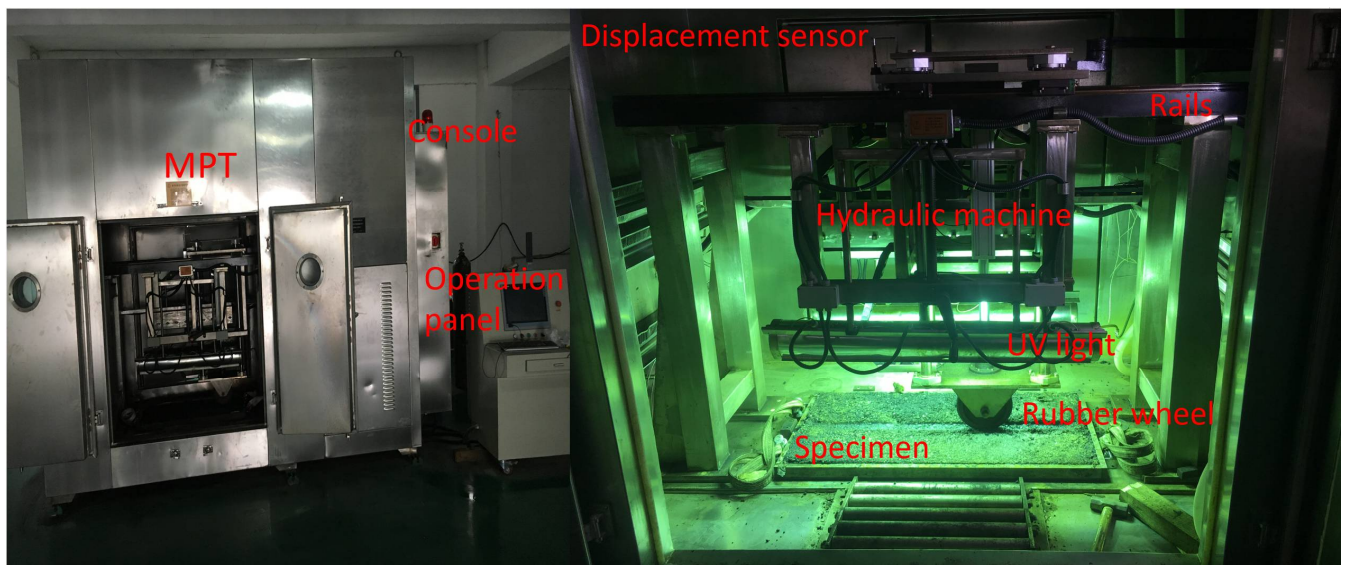

Figure 2. Multifunctional pavement material tester. 
In order to simulate the effect of long-term heavy loading, accelerated testing was adopted in this study to simulate the performance degradation of SHMA under heavy loading. The time-temperature superposition and thermorheological simplicity principles were commonly used to analyze the performance of asphalt and its mixture [29]. The WLF Equation (1) is a basic empirical formula based on the free volume theory by Williams, Landel and Ferry [30].

$$
\lg \alpha_{\mathrm{T}}=\frac{-\mathrm{C}_{1}\left(\mathrm{~T}-\mathrm{T}_{0}\right)}{\mathrm{C}_{2}+\left(\mathrm{T}-\mathrm{T}_{0}\right)} .
$$

where $C_{1}$ and $C_{2}$ are constants of the corresponding materials, $T$ is the shift temperature, $\mathrm{T}_{0}$ is the reference temperature, $\lg \alpha_{\mathrm{T}}=\lg \mathrm{t}_{0}-\lg \mathrm{t}, \mathrm{t}_{0}$ and $\mathrm{t}$ are the corresponding times of $\mathrm{T}_{0}$ and $\mathrm{T}$.

Therefore, the reference temperature $\mathrm{T}_{0}$ was set to $60{ }^{\circ} \mathrm{C}$ in the MPT to accelerate the process. The shift temperature $\mathrm{T}$ was set to the average annual road surface temperature $54.6{ }^{\circ} \mathrm{C}$ in Wuhan, a city in central China. By substituting the constants $\mathrm{C}_{1}=38.46$ and $C_{2}=316.35$ of asphalt mixture into Equation (1) [31], the corresponding relationship between the simulation time in the MPT and the real time $t_{0} / t=4.655$ could be obtained.

According to the investigation of traffic around the city, the volume of heavy-load trucks (axle load $\geq 1.2 \mathrm{MPa}$ ) was 1500 per day approximately. The vehicle model adopted a double rectangular uniformly distributed load. The coefficient of lanes was 0.5 . It was assumed that the width of the tire was $215 \mathrm{~mm}$, the flat ratio was 70\%, and the speed was $90 \mathrm{~km} / \mathrm{h}(25 \mathrm{~m} / \mathrm{s})$. So, the tire-ground contact area was $215 \times 70 \%=150.5 \mathrm{~mm}$, the contact time for one point on the road was $150.5 / 25,000=0.006 \mathrm{~s}$ and the contact time per day was $0.006 \times 2 \times 1500 \times 0.5=9 \mathrm{~s}$ per day. In the simulated condition, the width of rubber tire was $40 \mathrm{~mm}$, the flat ratio was $75 \%$, and the speed was $24 \mathrm{~m} / \mathrm{min}$. The contact time per hour in the MPT was calculated to be $108 \mathrm{~s}$ in the same way. Therefore, $1 \mathrm{~h}$ in the MPT could simulate $108 \times 4.655 / 9=55.86$ days in real condition

\subsection{Aggregate Analysis System}

To research the different characteristics of basalt and steel slag aggregates, an aggregate image measurement system (AIMS) was used to collect data and analyze them. As shown in Figure 3, the AIMS is made up of two parts: a testing part to collect the image and a computer part to process the data. AMIS can quickly obtain and quantify aggregate shape characteristics: texture, sphericity and angularity.

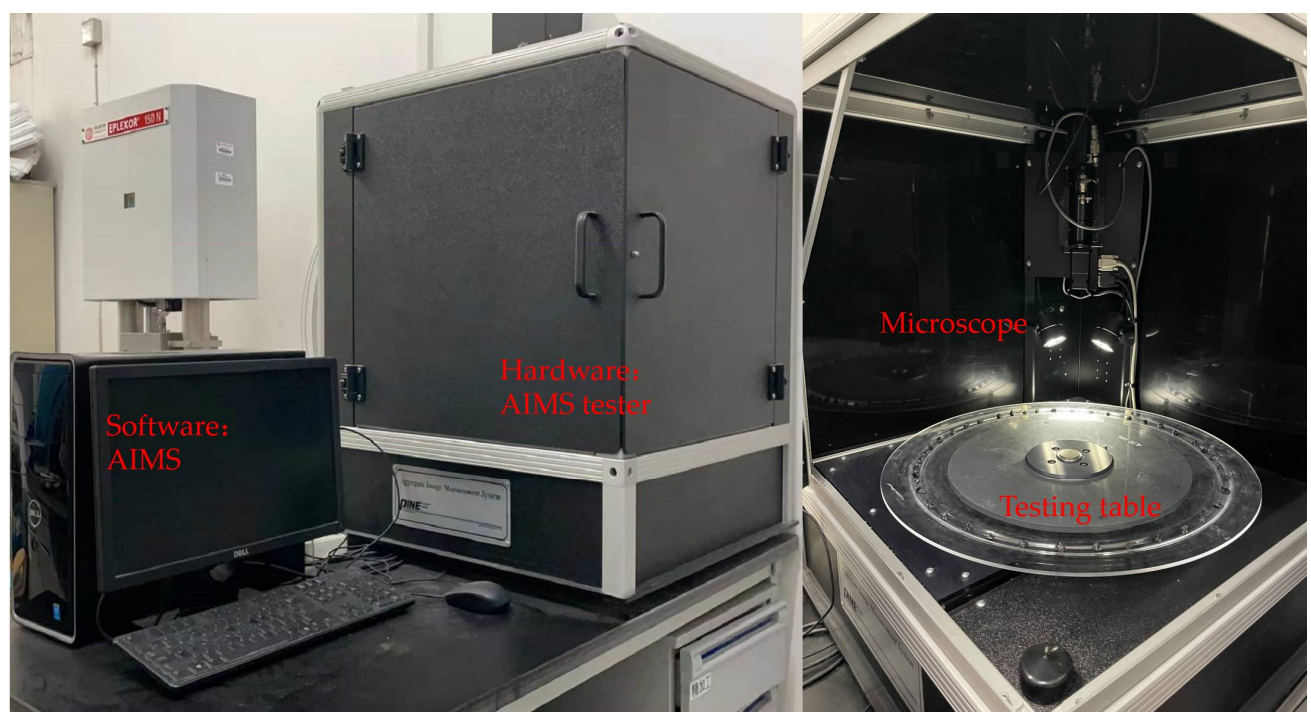

Figure 3. Aggregate image measurement system (AIMS) and its internal structure. 
Sphericity (SP) can describe the overall three-dimensional shape of a particle and determine whether it tends to be a sphere. Sphericity has a relative scale of 0 to 1 with a perfect sphere approaching a value of 1 . SP can be calculated with Equation (2).

$$
S P=\sqrt[3]{\frac{d_{S} d_{I}}{d_{L}^{2}}}
$$

where: $d_{S}=$ particle shortest dimension; $d_{I}=$ particle intermediate dimension; $d_{L}=$ particle longest dimension.

Gradient angularity (GA) describes whether particle boundaries are continuous and smooth. Higher gradient values indicate a more angular shape. Gradient angularity has a relative scale of 0 to 10,000 with an ideal circle having a value of 0 . The GA is analyzed by quantifying the change in the gradient on a particle boundary and is related to the sharpness of the corners in two-dimensional images of aggregate particles. The gradient method starts by calculating the inclination of gradient vectors on particle boundary points from the x-axis (horizontal axis in an image). GA can be calculated by Equation (3).

$$
\mathrm{GA}=\frac{1}{\frac{n}{3}-1} \sum_{i=1}^{\mathrm{n}-3}\left|\theta_{\mathrm{i}}-\theta_{\mathrm{i}+3}\right|
$$

where: $\theta=$ angle of orientation of the edge points; $\mathrm{n}=$ the total number of points; subscript $i$ denoting the ith point on the edge of the particle.

Texture (TX) describes the relative smoothness or roughness of aggregate particles' surfaces. AIMS uses the wavelet method to quantify texture. The wavelet analysis gives the texture details in the horizontal, vertical, and diagonal directions in three separate images. The texture index at a given decomposition level is the arithmetic mean of the squared values of the wavelet coefficients for all three directions. Texture has a relative scale of 0 to 1000 with a smooth polished surface having a value of 0 . The texture index is expressed mathematically as Equation (4).

$$
\mathrm{TX}=\frac{1}{3 \mathrm{~N}} \sum_{\mathrm{i}=1}^{3} \sum_{\mathrm{j}=1}^{\mathrm{N}}\left(\mathrm{D}_{\mathrm{i}, \mathrm{j}}(\mathrm{x}, \mathrm{y})\right)^{2}
$$

where: $\mathrm{D}=$ decomposition function; $\mathrm{n}=$ decomposition level; $\mathrm{N}=$ total number of coefficients in an image; $i=1,2$ or 3 for detailed images; $j=$ wavelet index; $x, y=$ location of the coefficients in the transformed domain.

\subsection{Testing Projects and Methods}

A survey report about Chinese highway transportation showed that the pressure applied by heavy trucks on the pavement was generally between 1.2 MPa and 1.7 MPa. Therefore, a value of 1.4 MPa was selected to simulate the overload condition [32]. SHMA specimens would be ground for 12-108 h under set point to observe the degradation. Each specimen would undergo 8640-77,760 times of wheel rolling. According to the accelerating test above, those tests could simulate $2-16$ years of service life in real condition.

Permanent deformation is connected with the mechanical strength of an asphalt pavement. The test can evaluate the stability and durability of the mixture. Texture depth (TD) and British pendulum number $(\mathrm{BPN})$ can reflect the texture and skid resistance of the pavement indirectly [33]. The test of TD and BPN can compendiously describe the micro and macro texture and friction coefficient, respectively. Therefore, permanent deformation, TD and BPN were selected as three indexes to measure the degradation of SHMA under heavy loading. The specimens were divided and dissolved by methylbenzene to separate aggregate from asphalt binder. The separate aggregate was sieved to analyze the variation of steel slag aggregate after heavy loading.

Figure 4 presents the prepared specimens in and after the fatigue test. The ground parts of the specimens were extracted to study the degradation under heavy loading. 


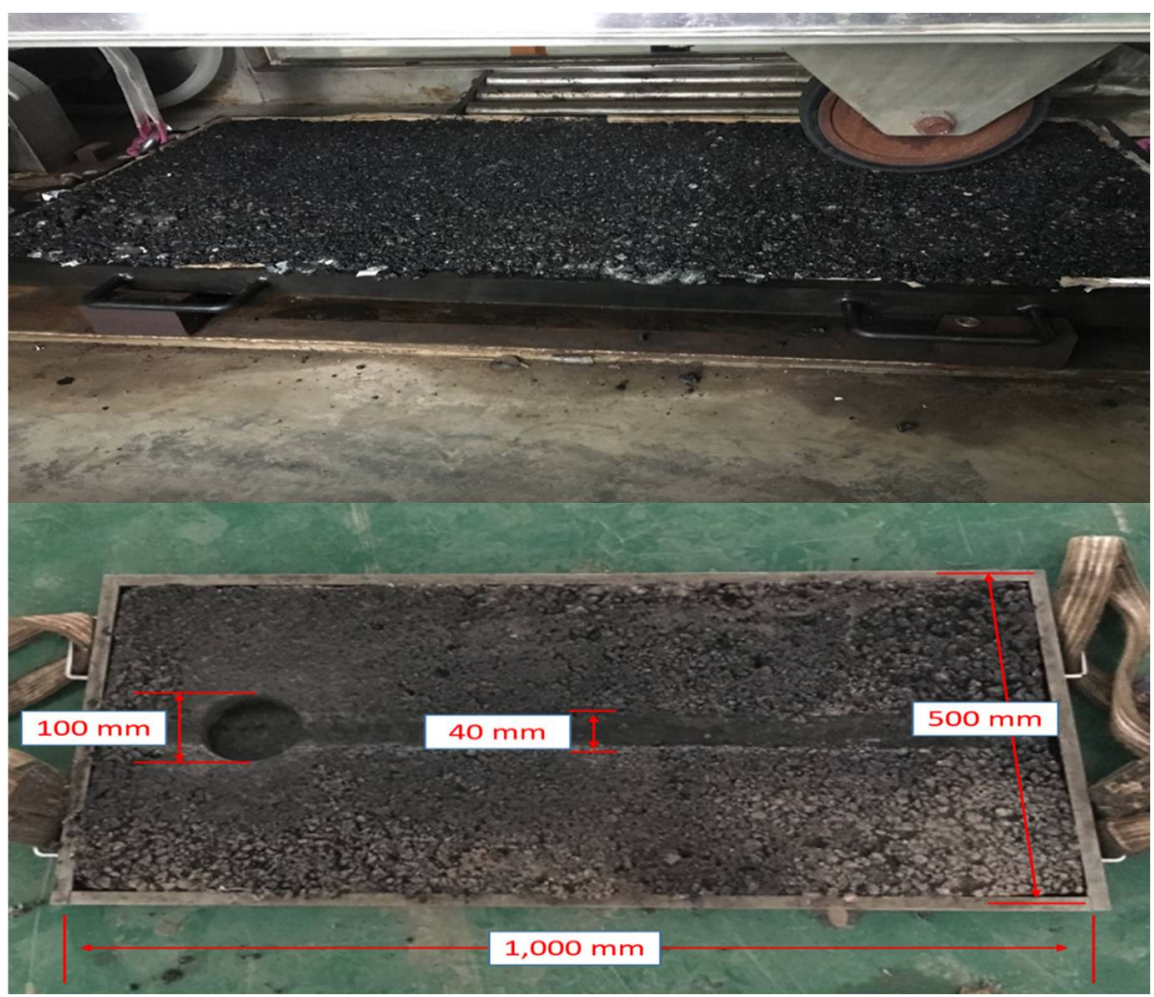

Figure 4. Specimens in and after the test.

\section{Experimental Results and Discussion}

3.1. Aggregate Analysis Results

Coarse aggregates of sizes $4.75-9.5 \mathrm{~mm}$ and $9.5-16 \mathrm{~mm}$ were selected as a typical example to research the particle characteristics using the AIMS. The aggregate analysis results are shown in Table 5.

Table 5. Aggregate analysis results.

\begin{tabular}{ccccc}
\hline \multicolumn{2}{c}{ Aggregate } & SP & GA & TX \\
\hline \multirow{2}{*}{ Basalt } & $9.5-16 \mathrm{~mm}$ & 0.735 & 2965 & 356 \\
\multirow{2}{*}{ Steel slag } & $4.75-9.5 \mathrm{~mm}$ & 0.673 & 2846 & 421 \\
& $9.5-16 \mathrm{~mm}$ & 0.704 & 3264 & 718 \\
& $4.75-9.5 \mathrm{~mm}$ & 0.636 & 3151 & 771 \\
\hline
\end{tabular}

As shown in Table 4, for the same aggregate, SP and GA decreased with the decline of aggregate particle size, while TX increased. By comparing the particle characteristics of basalt and steel slag, it could be found that steel slag aggregate had a lower SP, higher GA and TX. Analysis results illustrated there was not much difference between basalt and steel slag in sphericity, but steel slag was significantly higher than basalt in angularity and texture. Steel slag aggregate had the particle characteristics of low sphericity, high angularity and rich surface texture.

Figure 5 showed the typical characteristics of basalt aggregate and steel slag aggregate. It can also be observed in the figure that basalt aggregate had a smoother surface and fewer edges. Conversely, there were abundant pores and edges on the surface of the steel slag aggregate. 


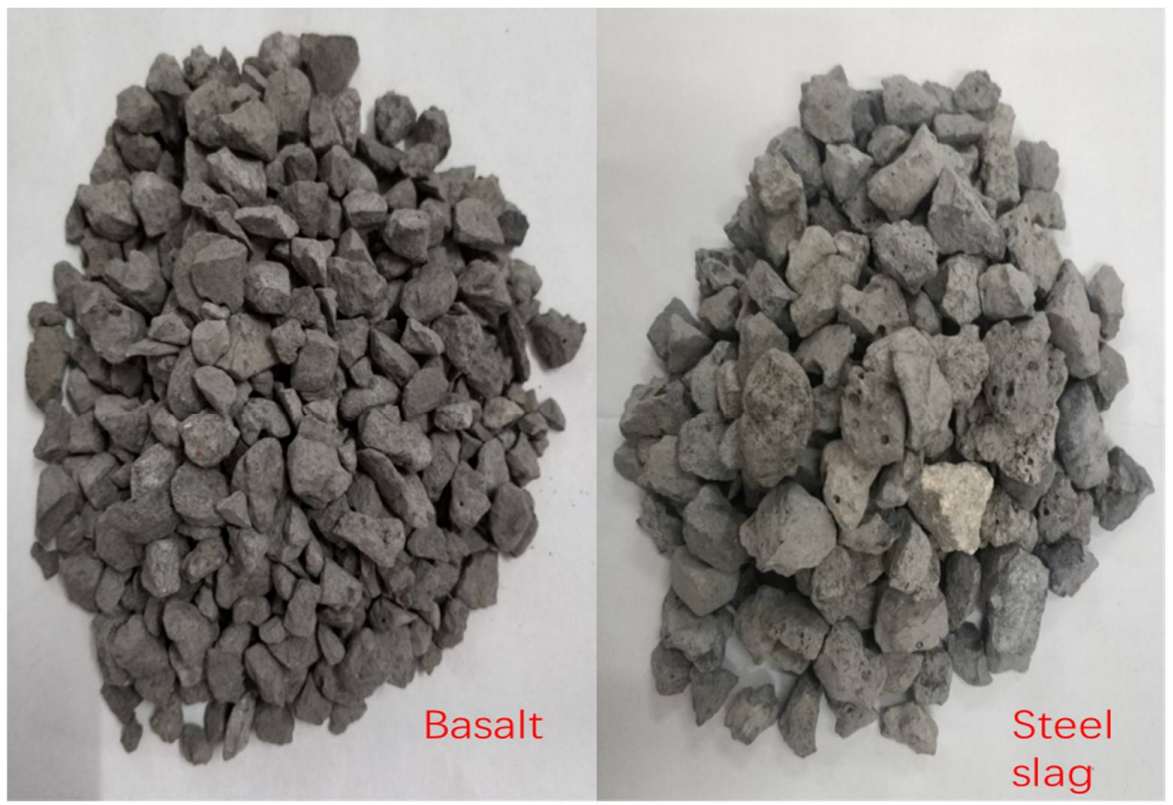

Figure 5. Basalt and steel slag aggregate.

\subsection{Results from Fatigue Test}

Figure 6 shows the effects on the development of rutting of various asphalt pavements under a pressure of 1.4 MPa. Each series was constituted by five periods of cumulative cycles.

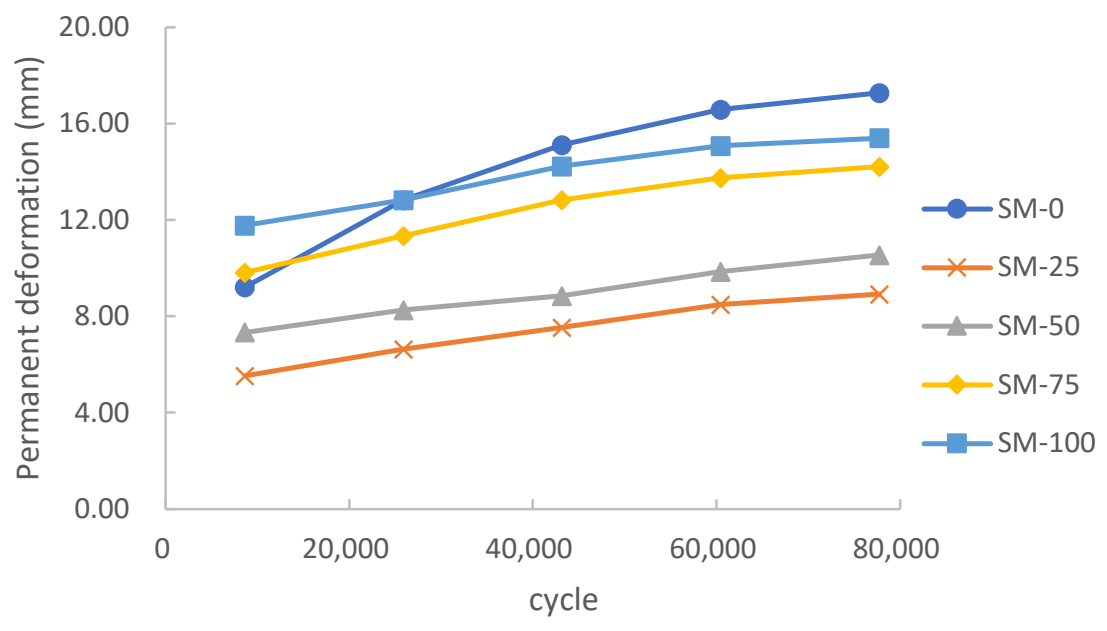

Figure 6. Effect of steel slag content on permanent deformation.

Normally, the rutting development of asphalt pavement can be divided into three stages: initial stage, steady stage and destruction stage [34]. In the first stage, the permanent deformation increases gradually, then it goes into the second stage, a period of stability. The rutting grows slowly at a steady rate during this time. Finally, the rutting and its growth rate continue to increase until its failure.

As shown in Figure 6, the permanent deformation curve of four specimens with steel slag were in the steady stage during the test. This illustrated that they passed through their initial stage before the first date collection ( 8640 cycles). Comparatively, the only specimens without steel slag added, SM-0, was still in its initial stage at the beginning of the test. According to the trend of the SM- 0 curve, it would have ended its initial stage at around 40,000 cycles of wheel rolling.

By comparing the initial ( 8640 cycles) and final ( 77,760 cycles) deformation values of five series, it could be found that the initial value of most series was about $60-70 \%$ of the 
final value, except for the SM-0 series without the addition of steel slag, whose initial value was only $53 \%$ of the final value.

The wheel tracking slope (WTS) could be used to describe the increase in permanent deformation [35]. The WTS was calculated by Equation (5).

$$
\text { WTS }=\frac{h_{\text {cycle } 1}-h_{\text {cycle } 2}}{\text { cycle } 1-\text { cycle } 2}
$$

where $\mathrm{h}_{\text {cycle }}$ is the depth of deformation in the cycle.

According to the calculation, the WTS of the four series with steel slag was about $0.5-0.6 \mathrm{~mm} /(104$ cycles $)$, which was much less than the WTS of $1.17 \mathrm{~mm} /(104$ cycles $)$ in the SM-0 series. This illustrates that the addition of steel slag could significantly decrease the evolution of permanent deformation on the pavement.

According to JTJ073.2-2001 [36], the allowance of deformation is no higher than $15 \mathrm{~mm}$ on highways. Once the deformation exceeds $15 \mathrm{~mm}$, the pavement is at risk of failure and needs major repair. Experimental results showed that the asphalt mixture with a part of steel slag (SM-25, SM-50, SM-75) would not exceed the limit under heavy loading in long-term service time. However, the mixture without steel slag (SM-0) and the mixture with pure steel slag (SM-100) were unable to be in service under heavy loading for long. This indicated that partial replacement of steel slag improved the performance, but all replacements resulted in a performance decline.

The above results showed that the addition of steel slag could significantly accelerate the process of the initial stage and reduce the final permanent deformation of the asphalt pavement, enhancing its mechanical properties, especially at low amounts of steel slag addition. According to the test results, the optimum addition amount of steel slag was $25 \%$, which could reduce the permanent deformation by $48.2 \%$. Due to its higher strength and angularity and richer surface texture, steel slag could bond better with asphalt binder at low amounts of steel slag addition, which provided stronger mechanical properties. However, with the increase of steel slag content, the voids in the steel slag absorbed asphalt in abundance. This decreased the amount of asphalt that acted as binder, resulting in a strength decline of the asphalt mixture.

Figure 7 shows two cross-section views of SHMA after a wheel-rolling test. The angularity and voids of the steel slag are presented in the figure.

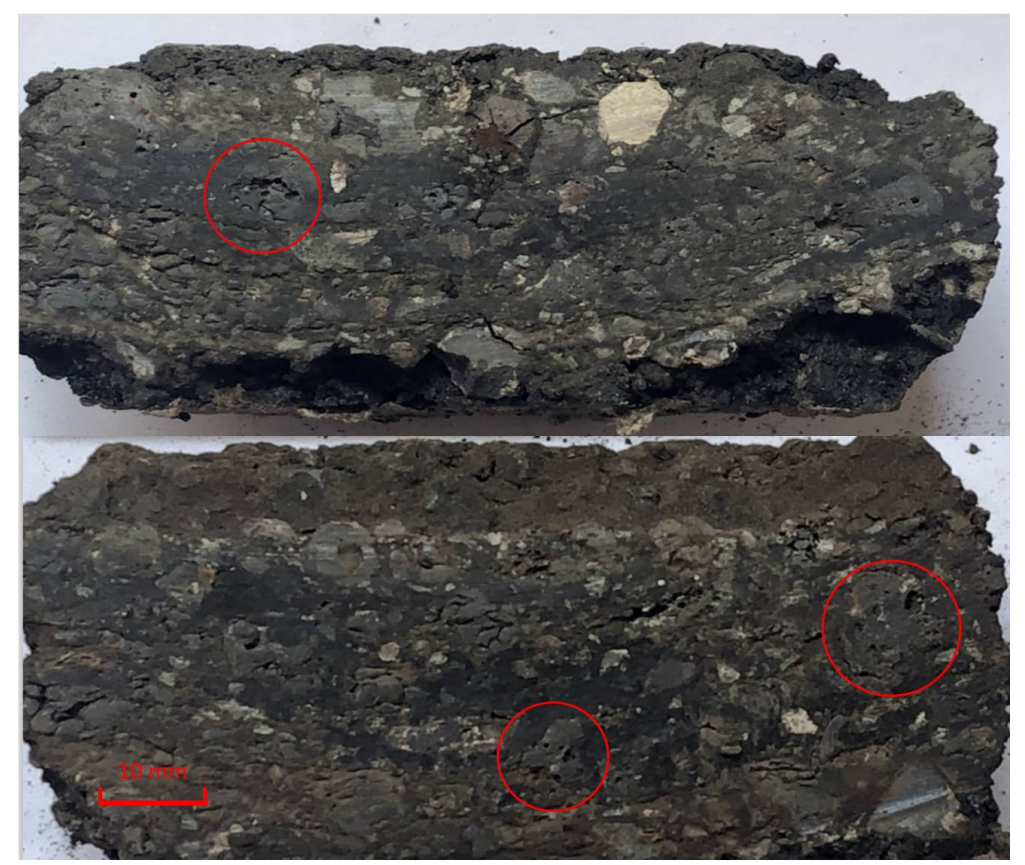

Figure 7. Cross-section view of SHMA. 


\subsection{Skid Resistance Results}

Figure 8 shows the variation in BPN of the asphalt mixture with different content of steel slag aggregate. Generally, a large BPN means that the pavement can provide higher friction, which means a better skid resistance.

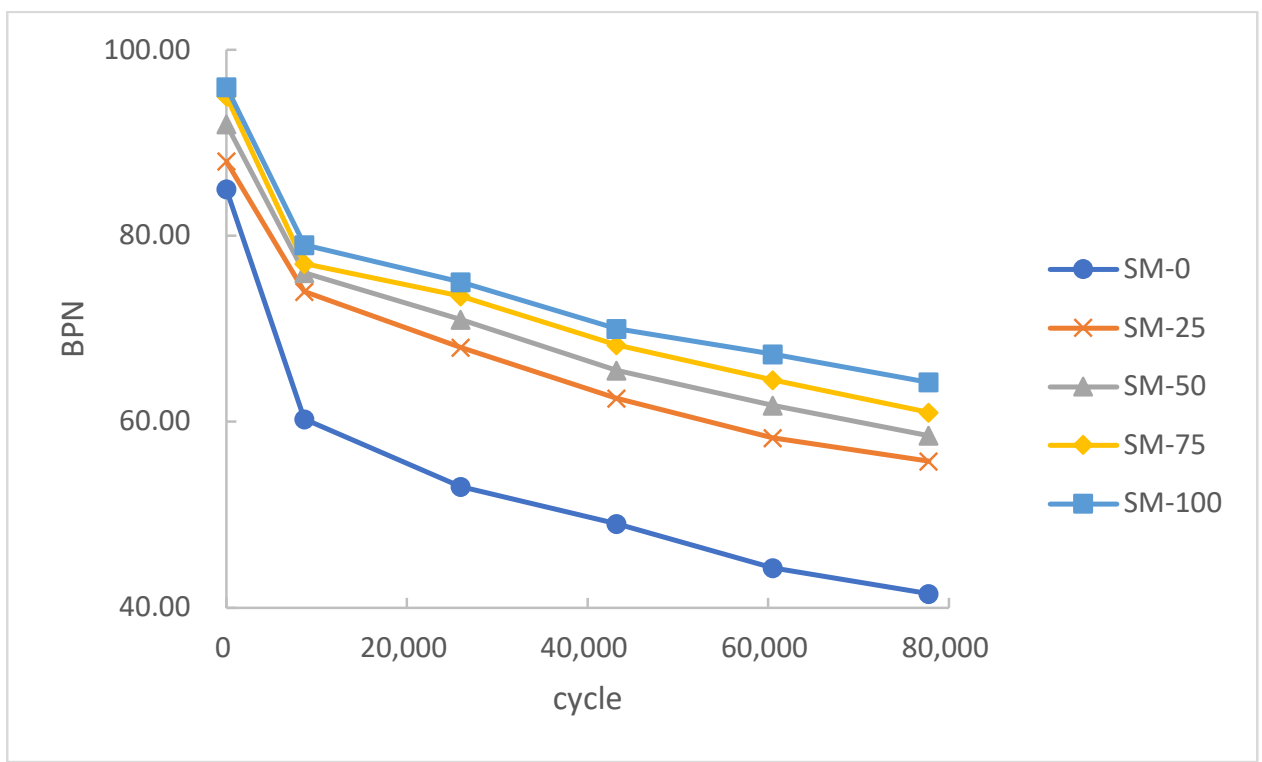

Figure 8. Effect of steel slag content on BPN.

As presented in Figure 8, at the initial stage, BPN decreased rapidly and stabilized gradually. In all five series, the BPN of SM-0 was much lower than in the other series. This result suggested that the addition of steel slag could significantly improve the skid resistance of the asphalt mixture. Moreover, the addition of steel slag could also contribute to reducing skid resistance loss. Experimental results showed that the final BPN of SM-0 decreased by $51.2 \%$. However, the final BPN of the other series with steel slag decreased by $33.3-36.6 \%$ to a varying degree.

It was found that the five series had a similar initial BPN. After a period of wheel grinding, the asphalt mixture on the surface was compacted to expose the edges of the inner aggregate. After that, the aggregate corners and edges without mixture protection were gradually destroyed by the wheel, which resulted in the rapid decline of skid resistance. Due to its higher strength and angularity, steel slag could retain more edges and corners after wheel grinding under heavy loading. Therefore, the higher content of steel slag could provide better skid resistance.

According to JTJ073.2-2001 [36], the BPN on highway should be higher than 45. Obviously, SM-0, the specimen without addition of steel slag, could not meet the requirement of long-term service under heavy loading. Meanwhile, other asphalt mixtures with steel slag can satisfy this requirement.

The TD showed a similar variation to BPN according to Figure 9. The asphalt mixture was compacted to expose the corners and edges of aggregates on the surface at the beginning. The destruction of the initial structure resulted in the rapid decline of the TD. Then, the edges and corners on the aggregates were ground off and the aggregates were gradually crushed into pieces by heavy loading, leading to a further decline of the TD in the later stage. In this process, the abundant pores in the steel slag could enrich the surface texture of the asphalt mixture. However, this improvement was not noticeable under long-term heavy loading. Therefore, the TD increased slightly with the increase of steel slag content. 


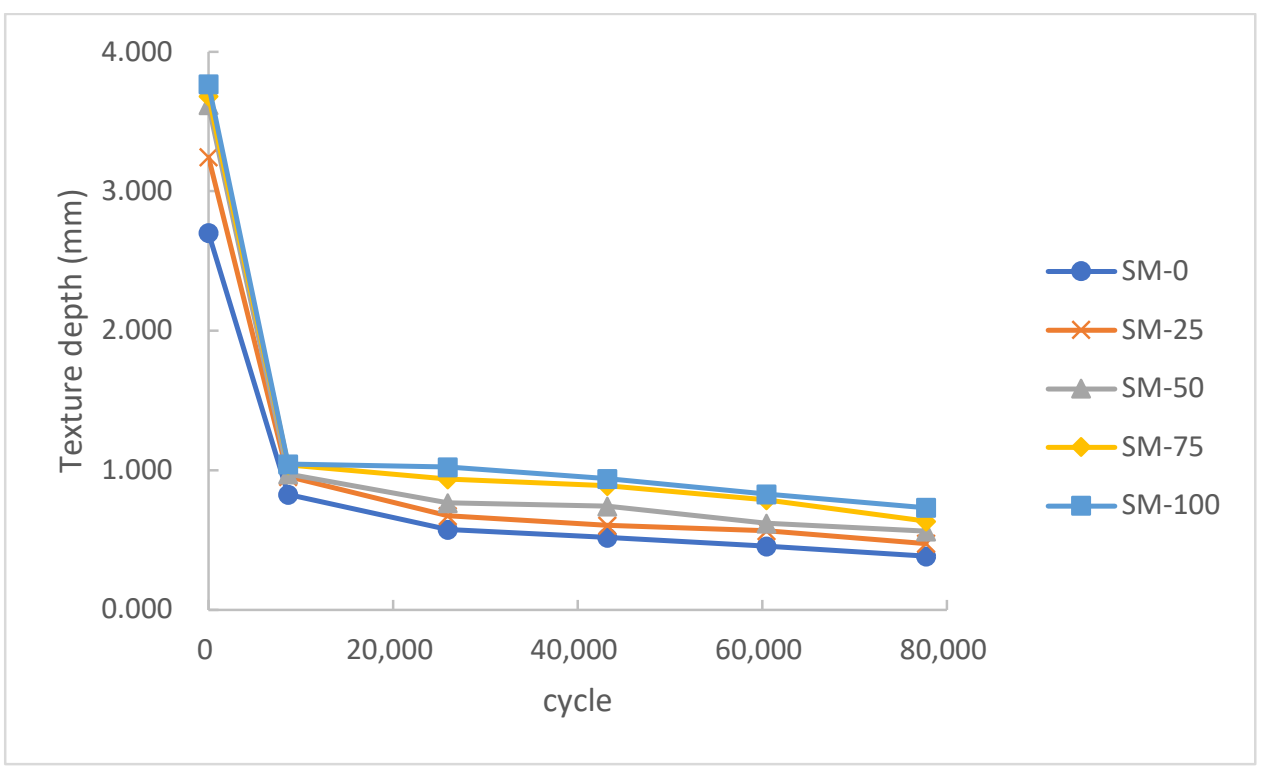

Figure 9. Effect of steel slag content on texture depth.

The skid resistance degradation mechanism of SHMA can be summarized according to the experimental results. The steel slag aggregate on the surface of the mixture was ground and the edges were worn off due to its particle characteristics under heavy loading. The polished aggregate led to a decline in skid resistance. However, because of the better angularity and texture of steel slag, the skid resistance of SHMA was still superior to BHMA after heavy loading service.

According to some relevant studies, the TD of an asphalt mixture mainly depends on its type and curve of aggregate grading [37]. Compared with the grading type, the coarse aggregate type had little effect on skid resistance. Therefore, the aggregate grading type should be given priority to improve the skid resistance. However, replacing coarse aggregate with steel slag could be a good supplement to the skid resistance of the asphalt mixture.

According to JTG D50-2006 [38], the allowance for TD on highways should be higher than $0.55 \mathrm{~mm}$. Likewise, asphalt mixtures without steel slag were not able to serve in the long term under heavy loading. The mixtures with steel slag could accomplish this task well.

\subsection{Sieving Results}

Organic solvents were used to dissolve the asphalt in the samples to obtain the variation of aggregate grades after heavy loading test. Table 6 shows the sieving results of asphalt mixtures that underwent $108 \mathrm{~h}$ of heavy loading testing. In each series, $0 \#$ indicates the initial grade.

Due to the randomness of the sampling, these sieving results could not accurately describe the real grading, but they could reflect the changing trend of the grading under heavy loading. As shown in Table 6, the fine aggregates $(0-2.36 \mathrm{~mm})$ changed insignificantly after the test. Considering the loss of powdery aggregates in the separation process, it could be assumed that the fine aggregates had no loss or increase in the whole process.

As shown in Table 6, the content of the 9.5-16 mm, 4.75-9.5 mm, 2.36-4.75 mm aggregates in the mixtures changed significantly. The content of the $9.5-16 \mathrm{~mm}$ part decreased while the $4.75-9.5 \mathrm{~mm}$ and $2.36-4.75 \mathrm{~mm}$ parts increased. These results illustrate that the large-particle aggregates in the asphalt mixtures were crushed into pieces under heavy loading. It could also be observed in the cross section of Figure 7. 
Table 6. Sieving results of ground asphalt mixtures.

\begin{tabular}{|c|c|c|c|c|c|c|c|}
\hline \multirow{2}{*}{ Specimen } & \multirow{2}{*}{ Particle Size } & \multicolumn{6}{|c|}{ Label } \\
\hline & & 0 & 1 & 2 & 3 & 4 & 5 \\
\hline \multirow{5}{*}{ SM-0 } & $9.5-16 \mathrm{~mm}$ & $28.00 \%$ & $19.38 \%$ & $17.62 \%$ & $15.01 \%$ & $12.61 \%$ & $10.17 \%$ \\
\hline & $4.75-9.5 \mathrm{~mm}$ & $28.00 \%$ & $33.34 \%$ & $33.65 \%$ & $34.26 \%$ & $36.22 \%$ & $36.40 \%$ \\
\hline & $2.36-4.75 \mathrm{~mm}$ & $14.00 \%$ & $19.51 \%$ & $19.85 \%$ & $22.87 \%$ & $23.02 \%$ & $23.37 \%$ \\
\hline & $0-2.36 \mathrm{~mm}$ & $30.00 \%$ & $27.77 \%$ & $28.89 \%$ & $27.86 \%$ & $28.16 \%$ & $30.06 \%$ \\
\hline & $9.5-16 \mathrm{~mm}$ & $28.26 \%$ & $21.04 \%$ & $19.50 \%$ & $18.63 \%$ & $18.40 \%$ & $16.65 \%$ \\
\hline \multirow{3}{*}{ SM-25 } & $4.75-9.5 \mathrm{~mm}$ & $28.11 \%$ & $32.57 \%$ & $33.25 \%$ & $32.96 \%$ & $32.67 \%$ & $32.68 \%$ \\
\hline & $2.36-4.75 \mathrm{~mm}$ & $14.32 \%$ & $19.61 \%$ & $21.99 \%$ & $21.49 \%$ & $21.05 \%$ & $23.70 \%$ \\
\hline & $0-2.36 \mathrm{~mm}$ & $29.37 \%$ & $26.78 \%$ & $25.26 \%$ & $26.92 \%$ & $27.88 \%$ & $26.97 \%$ \\
\hline \multirow{5}{*}{ SM-50 } & $9.5-16 \mathrm{~mm}$ & $28.53 \%$ & $20.49 \%$ & $17.36 \%$ & $14.66 \%$ & $11.10 \%$ & $10.50 \%$ \\
\hline & $4.75-9.5 \mathrm{~mm}$ & $28.22 \%$ & $31.01 \%$ & $36.50 \%$ & $37.20 \%$ & $39.92 \%$ & $38.54 \%$ \\
\hline & $2.36-4.75 \mathrm{~mm}$ & $14.62 \%$ & $21.47 \%$ & $21.08 \%$ & $22.68 \%$ & $23.51 \%$ & $24.74 \%$ \\
\hline & $0-2.36 \mathrm{~mm}$ & $28.63 \%$ & $27.03 \%$ & $25.06 \%$ & $25.46 \%$ & $25.47 \%$ & $26.22 \%$ \\
\hline & $9.5-16 \mathrm{~mm}$ & $28.79 \%$ & $20.56 \%$ & $15.34 \%$ & $12.98 \%$ & $9.88 \%$ & $8.23 \%$ \\
\hline \multirow{3}{*}{ SM-75 } & $4.75-9.5 \mathrm{~mm}$ & $28.33 \%$ & $31.25 \%$ & $35.64 \%$ & $36.78 \%$ & $38.65 \%$ & $39.42 \%$ \\
\hline & $2.36-4.75 \mathrm{~mm}$ & $14.92 \%$ & $21.23 \%$ & $22.65 \%$ & $23.51 \%$ & $24.32 \%$ & $25.41 \%$ \\
\hline & $0-2.36 \mathrm{~mm}$ & $27.96 \%$ & $26.96 \%$ & $26.37 \%$ & $26.73 \%$ & $27.96 \%$ & $26.94 \%$ \\
\hline \multirow{4}{*}{ SM-100 } & $9.5-16 \mathrm{~mm}$ & $29.00 \%$ & $20.37 \%$ & $14.68 \%$ & $13.55 \%$ & $9.93 \%$ & $7.53 \%$ \\
\hline & $4.75-9.5 \mathrm{~mm}$ & $29.00 \%$ & $31.26 \%$ & $34.84 \%$ & $33.47 \%$ & $38.19 \%$ & $39.84 \%$ \\
\hline & $2.36-4.75 \mathrm{~mm}$ & $15.00 \%$ & $20.78 \%$ & $21.43 \%$ & $23.88 \%$ & $24.55 \%$ & $26.34 \%$ \\
\hline & $0-2.36 \mathrm{~mm}$ & $27.00 \%$ & $27.59 \%$ & $29.04 \%$ & $29.10 \%$ & $27.33 \%$ & $26.29 \%$ \\
\hline
\end{tabular}

The 9.5-16 $\mathrm{mm}$ aggregate was pressed by heavy loading and broke into smaller pieces. The $4.75-9.5 \mathrm{~mm}$ aggregate was crushed by heavy loading and reduced, on the one hand; On the other hand, it received pieces from the crushed $4.75-9.5 \mathrm{~mm}$ aggregate and increased. As the result, the content of the $4.75-9.5 \mathrm{~mm}$ aggregate increased as well as the 2.36-4.75 mm aggregate. It could be found that the increments of $4.75-9.5 \mathrm{~mm}$ and 2.36-4.75 $\mathrm{mm}$ aggregates were about half of the loss of the $9.5-16 \mathrm{~mm}$ aggregate. As a result, it could be assumed that half of the crushed 9.5-16 mm aggregate became 4.75-9.5 mm aggregate and the other half became $2.36-4.75 \mathrm{~mm}$ aggregate. The main change in asphalt mixture was the crushing of the $9.5-16 \mathrm{~mm}$ aggregate.

The variation in 9.5-16 mm aggregate is demonstrated in Figure 10. It could be observed that the final content of $9.5-16 \mathrm{~mm}$ aggregate after heavy loading decreased with the increase of the steel slag content. Although steel slag had a higher strength, its irregular shape caused stress concentration and broke more easily. Therefore, steel slag was more likely to be crushed under heavy loading than basalt aggregate.

SM-25 had the highest final content of $9.5-16 \mathrm{~mm}$ aggregate. Moreover, SM-25 had the highest deformation resistance according to the permanent deformation results. In order to verify whether there is a correlation between permanent deformation and the content of 9.5-16 mm aggregate, a Pearson correlation coefficient (PCC) test was conducted by SPSS (Statistical Product and Service Solutions). The PCC test is a measure of the linear correlation between two variables, $X$ and Y. The PCC has a value between 1 and -1 , where 1 is total positive correlation, 0 is no correlation, and -1 is total negative correlation. The PCC can be computed by Equation (6).

$$
r_{x y}=\frac{\sum_{i=1}^{n}\left(x_{i}-\bar{x}\right)\left(y_{i}-\bar{y}\right)}{\sqrt{\sum_{i=1}^{n}\left(x_{i}-\bar{x}\right)^{2}} \sqrt{\sum_{i=1}^{n}\left(y_{i}-\bar{y}\right)^{2}}}
$$

where $r_{x y}$ is the PCC; $n$ is the sample size; $x i$, yi are the individual samples; $\bar{x}=\frac{1}{n} \sum_{i=1}^{n} x_{i}$, analogously for $\bar{y}$. 


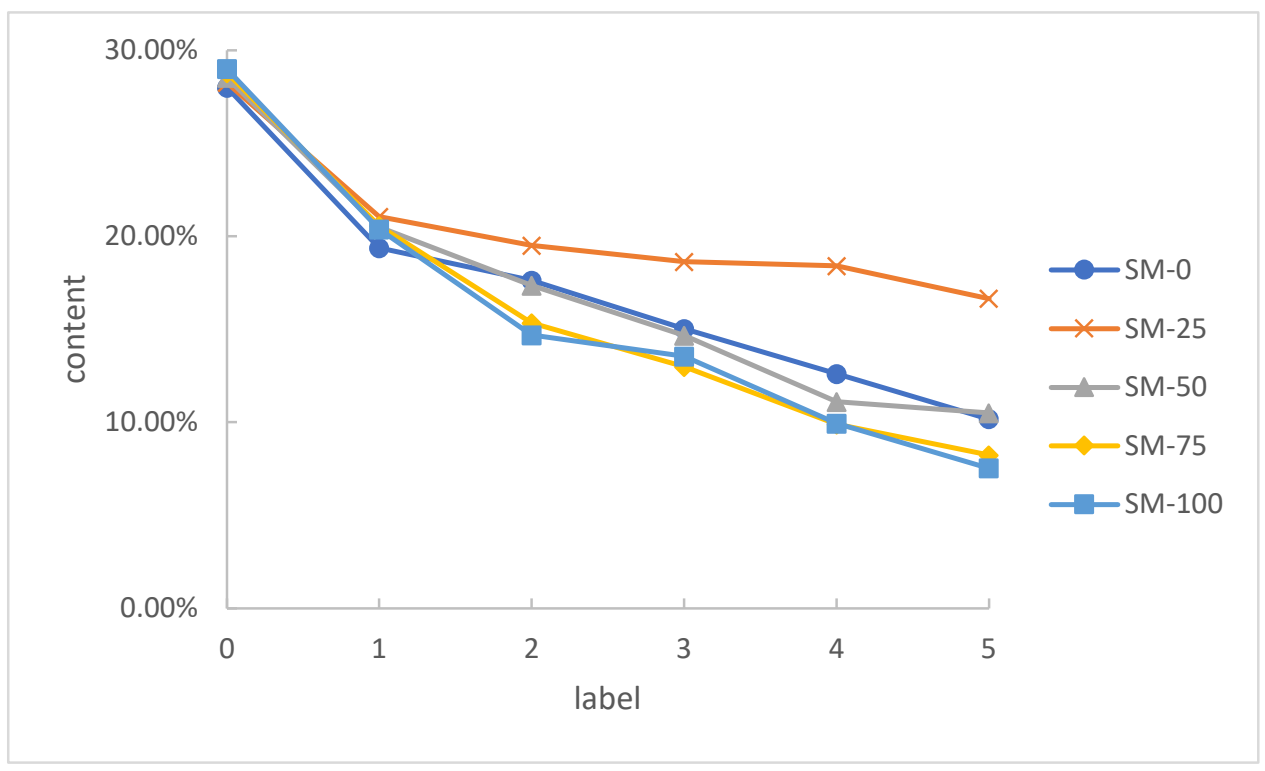

Figure 10. Variations in $9.5-16 \mathrm{~mm}$ aggregate content.

The contents of $9.5-16 \mathrm{~mm}, 4.75-9.5 \mathrm{~mm}$ and $2.36-4.75 \mathrm{~mm}$ aggregates were taken as variables to conduct the PCC test with permanent deformation. The analysis results are shown in Table 7.

Table 7. PCC test results.

\begin{tabular}{cccc}
\hline & $\mathbf{9 . 5}-\mathbf{1 6} \mathbf{~ m m}$ & $\mathbf{4 . 7 5 - 9 . 5 ~} \mathbf{~ m m}$ & $\mathbf{2 . 3 6 - 4 . 7 5 ~} \mathbf{~ m m}$ \\
\hline PCC & -0.727 & 0.475 & 0.569 \\
Sig. & 0.000039 & 0.16 & 0.003 \\
\hline
\end{tabular}

It can be seen that the content of 9.5-16 mm aggregate had the highest PCC with permanent deformation, and it could pass a significance test at the 0.01 level. It illustrated that there was a fairly strong correlation between the content of $9.5-16 \mathrm{~mm}$ aggregate and the permanent deformation of asphalt mixture.

The large aggregates in asphalt mixtures with a high content of steel slag were easier to crush under heavy loading. Therefore, the asphalt with a high content of steel slag did not have enough large aggregates to support its strength after heavy loading service. That could be another important reason why the deformation resistance of asphalt mixtures with a high content of steel slag was inferior to those asphalt mixtures with a low content of steel slag.

The mechanism of degradation of SHMA can be summarized based on the above results. Large steel slag aggregates were crushed under heavy loading due to their particle characteristics. The broken aggregates moved in the mixture and formed a new stable skeleton structure, which led to the decline of deformation resistance.

\section{Conclusions}

Large-sized specimen wheel tracking testing on AC-13 asphalt mixtures with various contents of steel slag was carried out to study the performance degradation under heavy loading conditions. The following results were obtained:

(1) Steel slag aggregates have high strength, abundant angularity and rich surface texture characteristics. The degradation of asphalt mixtures under heavy loading can be effectively reduced after the addition of steel slag.

(2) The addition of steel slag aggregate to the asphalt mixture can reinforce the resistance to deformation and skid under heavy loading. Permanent deformation on SHMA 
can be decreased by $48.2 \%$ with a low content of $25 \%$ steel slag. A high steel slag content reduces the asphalt that acts as a binder, resulting in the loss in strength of the asphalt mixture. The abrasion and polishing of steel slag aggregate on the surface was a main cause for the decline of skid resistance under heavy loading. The performance of SHMA can still meet the pavement technical requirement after long-term heavy loading service.

(3) The sieving results indicate that the main change that occurs in the asphalt mixture under heavy loading service is the crushing of the $9.5-16 \mathrm{~mm}$ aggregate. The fracture of large particles forms a new aggregate grading and changes the properties of the asphalt mixture. The content of $9.5-16 \mathrm{~mm}$ aggregate has a great influence on permanent deformation. Steel slag is more likely to be broken into smaller particles under heavy loading, which is also an important reason for the lower resistance to deformation of the asphalt mixture with a high content of steel slag.

(4) The mechanism of deformation resistance degradation of SHMA under heavy loading can be summarized as follows: the large aggregate was crushed and formed a new aggregate skeleton structure.

Author Contributions: Conceptualization, J.L.; data curation, J.L.; formal analysis, J.L. and J.X.; methodology, J.L. and J.X.; supervision, S.W.; investigation, J.L. and J.Y.; resources, J.Y. and S.W.; writing-original draft, J.L.; writing-review and editing, J.X. All authors have read and agreed to the published version of the manuscript.

Funding: This research was funded by the National Natural Science Foundation of China (7181101180), Major Science and Technology Projects of Inner Mongolia Autonomous Region (zdzx2018029), Key R\&D Program of Hubei Province (2020BCB064), Technological Innovation Major Project of Hubei Province (2019AEE023).

Acknowledgments: This study is sponsored in part by the National Natural Science Foundation of China (7181101180), Major Science and Technology Projects of Inner Mongolia Autonomous Region (zdzx2018029), Key R\&D Program of Hubei Province (2020BCB064), Technological Innovation Major Project of Hubei Province (2019AEE023), to which the authors are very grateful.

Conflicts of Interest: The authors declare no conflict of interest.

\section{References}

1. Oluwasola, E.A.; Hainin, M.R.; Aziz, M.M.A.; Yaacob, H.; Warid, M.N.M. Potentials of steel slag and copper mine tailings as construction materials. Mater. Res. Innov. 2014, 18 (Suppl. 6), S6-250-S6-254. [CrossRef]

2. Aziz, M.M.A.; Hainin, M.R.; Yaacob, H.; Ali, Z.; Chang, F.L.; Adnan, A.M. Characterisation and utilisation of steel slag for the construction of roads and highways. Mater. Res. Innov. 2014, 18 (Suppl. 6), S6-255-S6-259. [CrossRef]

3. Jo, S.H.; Kim, K.; Kim, N. A study on aggregate grading of $10 \mathrm{~mm}$ dense-graded asphalt mixture using slag aggregate. J. Korean Soc. Civ. Eng. 2015, 35, 1367-1375. [CrossRef]

4. Yüksel, İ. A review of steel slag usage in construction industry for sustainable development. Environ. Dev. Sustain. 2017, 19, 369-384. [CrossRef]

5. Shi, C. Steel slag—its production, processing, characteristics, and cementitious properties. J. Mater. Civ. Eng. 2004, 16, 230-236. [CrossRef]

6. Asi, I.M.; Qasrawi, H.Y.; Shalabi, F.I. Use of steel slag aggregate in asphalt concrete mixes. Can. J. Civ. Eng. 2007, 34, 902-911. [CrossRef]

7. Oluwasola, E.A.; Hainin, M.R.; Aziz, M.M.A. Comparative evaluation of dense-graded and gap-graded asphalt mix incorporating electric arc furnace steel slag and copper mine tailings. J. Clean. Prod. 2016, 122, 315-325. [CrossRef]

8. Oluwasola, E.A.; Hainin, M.R.; Aziz, M.M. Evaluation of rutting potential and skid resistance of hot mix asphalt incorporating electric arc furnace steel slag and copper mine tailing. Indian J. Eng. Mater. Sci. 2015, 22, 550-558.

9. Pasetto, M.; Baldo, N. Performance comparative analysis of stone mastic asphalts with electric arc furnace steel slag: A laboratory evaluation. Mater. Struct. 2012, 45, 411-424. [CrossRef]

10. Kim, K.; Jo, S.H.; Kim, N.; Kim, H. Characteristics of hot mix asphalt containing steel slag aggregate according to temperature and void percentage. Constr. Build. Mater. 2018, 188, 1128-1136. [CrossRef]

11. Wu, S.; Xue, Y.; Ye, Q.; Chen, Y. Utilization of steel slag as aggregates for stone mastic asphalt (SMA) mixtures. Build. Environ. 2007, 42, 2580-2585. [CrossRef]

12. Xie, J.; Wu, S.; Lin, J.; Cai, J.; Chen, Z.; Wei, W. Recycling of basic oxygen furnace slag in asphalt mixture: Material characterization \& moisture damage investigation. Constr. Build. Mater. 2012, 36, 467-474. [CrossRef] 
13. Xie, J.; Chen, Z.; Pang, L.; Wu, S. Implementation of modified pull-off test by UTM to investigate bonding characteristics of bitumen and basic oxygen furnace slag (BOF). Constr. Build. Mater. 2014, 57, 61-68. [CrossRef]

14. Xie, J.; Chen, J.; Wu, S.; Lin, J.; Wei, W. Performance characteristics of asphalt mixture with basic oxygen furnace slag. Constr. Build. Mater. 2013, 38, 796-803. [CrossRef]

15. Kehagia, F. Skid resistance performance of asphalt wearing courses with electric arc furnace slag aggregates. Waste Manag. Res. 2009, 27, 288-294. [CrossRef] [PubMed]

16. Asi, I.M. Evaluating skid resistance of different asphalt concrete mixes. Build. Environ. 2007, 42, 325-329. [CrossRef]

17. Zhang, Q.; Chen, Y.; Li, X. Rutting in asphalt pavement under heavy loading and high temperature. In Proceedings of the "Asphalt Material Characterization, Accelerated Testing, and Highway Management", GeoHunan International Conference, Hunan, China, 15 September 2009; pp. 39-48. [CrossRef]

18. Javilla, B.; Mo, L.; Hao, F.; Shu, B.; Wu, S. Multi-stress loading effect on rutting performance of asphalt mixtures based on wheel tracking testing. Constr. Build. Mater. 2017, 148, 1-9. [CrossRef]

19. Rezaei, A.; Masad, E.; Chowdhury, A.; Harris, J.P. Predicting Asphalt Mixture Skid Resistance by Aggregate Characteristics and Grading. Transp. Res. Rec. 2009, 2104, 24-33. [CrossRef]

20. Horii, K. Overview of Iron, Steel Slag Application and Development of New Utilization Technologies; Nippon Steel Sumitomo Metal Technical Report; Nippon Steel Corporation: Tokyo, Japan, 2015; No. 109.

21. Mousavinezhad, S.H.; Shafabakhsh, G.H.; Ani, O.J. Nano-clay and styrene-butadiene-styrene modified bitumen for improvement of rutting performance in asphalt mixtures containing steel slag aggregates. Constr. Build. Mater. 2019, 226, 793-801. [CrossRef]

22. Cheng, Y.; Chai, C.; Liang, C.; Chen, Y. Mechanical Performance of Warm-Mixed Porous Asphalt Mixture with Steel Slag and Crumb-Rubber-SBS Modified Bitumen for Seasonal Frozen Regions. Materials 2019, 12, 857. [CrossRef]

23. Ye, Y.; Wu, S.; Li, C.; Kong, D.; Shu, B. Morphological Discrepancy of Various Basic Oxygen Furnace Steel Slags and Road Performance of Corresponding Asphalt Mixtures. Materials 2019, 12, 2322. [CrossRef]

24. GB/T 24765-2009; Steel Slag for Wearing Asphalt Pave. China National Standardization Management Committee: Beijing, China, 2009.

25. JTG E42-2005; Test Methods of Aggregates for Highway Engineering. Ministry of Transport: Beijing, China, 2005.

26. JTG E20-2011; Standard Test Methods of Bitumen and Bituminous Mixtures for Highway Engineering. Ministry of Transport: Beijing, China, 2011.

27. Chen, X.; Huang, B.; Xu, Z. Comparison between flat rubber wheeled loaded wheel tester and asphalt pavement analyzer. Road Mater. Pavement Des. 2007, 8, 595-604. [CrossRef]

28. Iskender, E.; Aksoy, A. Field and laboratory performance comparison for asphalt mixtures with different moisture conditioning systems. Constr. Build. Mater. 2012, 27, 45-53. [CrossRef]

29. Jaczewski, M.; Judycki, J.; Jaskula, P. Asphalt concrete subjected to long-time loading at low temperatures-Deviations from the time-temperature superposition principle. Constr. Build. Mater. 2019, 202, 426-439. [CrossRef]

30. Zhang, Q.; Zhao, J.; Guo, S. Asphalt Rheological Properties Transformation from Frequency Domain to Temperature Domain Based on WLF Equation. Int. J. Pavement Res. Technol. 2021. [CrossRef]

31. Yin, Y.; Huang, W.; Lv, J.; Ma, X.; Yan, J. Unified construction of dynamic rheological master curve of asphalts and asphalt mixtures. Int. J. Civ. Eng. 2018, 16, 1057-1067. [CrossRef]

32. Zhang, J.X.; Liu, L.H.; Wang, L.L. Influence of speed and texture depth on skid resistance of pavement surface. Beijing Univ. Technol. 2009, 35, 48-52.

33. Ahadi, M.R.; Nasirahmadi, K. The effect of asphalt concrete micro \& macro texture on skid resistance. Rehabil. Civil Eng. 2013, 1, 15-28. [CrossRef]

34. Witczak, M.W. Simple Performance Test for Superpave Mix Design; Transportation Research Board: Washington, DC, USA, 2002.

35. Morea, F.; Zerbino, R. Wheel tracking test (WTT) conducted under different standards. Study and correlation of test parameters and limits. Mater. Struct. 2015, 48, 4019-4028. [CrossRef]

36. JTJ073.2-2001; Technical Specification for Maintenance of Highway Asphalt Pavement. Ministry of Transport: Beijing, China, 2001.

37. Gao, L.; Liu, M.; Wang, Z.; Xie, J.; Jia, S. Correction of texture depth of porous asphalt pavement based on CT scanning technique. Constr. Build. Mater. 2019, 200, 514-520. [CrossRef]

38. JTG D50-2006; Specifications for Design of Highway Asphalt Pavement. Ministry of Transport: Beijing, China, 2006. 